\title{
The joint effects of two factors in the aetiology of oesophageal cancer in Japan
}

\author{
KEI NAKACHI, KAZUE IMAI, YOSHIHARU HOSHIYAMA, AND TAKAFUMI \\ SASA BA
}

From the Department of Epidemiology, Saitama Cancer Center Research Institute, 818 Komuro, Inamachi, Saitama, Japan

SUMMARY A multifactorial approach to the aetiology of oesophageal cancer was made on the basis of a case-control study in Saitama prefecture, Japan. The joint risks of two factors were calculated directly from joint distributions, following a dichotomous exposure model. Three models of factor combinations were taken into account: two risk enhancing factors, two risk reducing factors, and risk enhancing and reducing factors. We observed remarkable risk elevations in the first model, and the observed joint risks were in the neighbourhood of the multiplicative products of single acting risks of individual factors. The highest odds ratios of about 10 or more were found with combinations of salty foods, excessive intake of rice and alcohol abuse. The second and third models also followed a multiplicative modification of risk. The lowest odds ratios of less than 0.2 were observed in the second model, with combinations of fruits and raw vegetables, fruits and seaweed, and raw vegetables and meat. In the third model, the increased risk caused by an enhancing factor was reduced proportionately to the presence of a risk reducing factor. Finally the dose-response relations of two factors were observed and shown to be categorised into three typical patterns of risk modification, following a three exposure level model. These patterns could be explained by both the dose-response relations of individual factors and the multiplicative modification of risk.

Cancer of the oesophagus is characterised from an epidemiological viewpoint by a wide variation in mortality and incidence rates in different geographical regions, and among different races and sexes around the world. Most of affluent Western countries showed low rates of less than $5 / 100000$ for males, and higher sex ratios (male: female, 2-6). ${ }^{12}$ On the other hand, extremely high rates have been observed in the coastal regions of Iran, ${ }^{3}$ and in Transkei, ${ }^{4}$ Kazakhstan in USSR, ${ }^{5}$ Henan province of China, ${ }^{6}$ and other regions, with rates for males of more than $30 / 100000$, and lower sex ratios (0.8-2). Mortality rates in Japan are intermediate between these values: the age adjusted rates between 1978 and 1982 were on average $6.9 / 100000$ for males and 1.4 for females, with a sex ratio of 4.9 . Saitama prefecture had relatively high rates among the Japanese prefectures $(8.3$ for males and 1.8 for females).

This wide variation in the incidence and mortality of oesophageal cancer implies that environment factors are important in the aetiology. The predominant risk enhancing factors in the low risk areas were high alcohol consumption and cigarette smoking. ${ }^{78}$ On the other hand the main risk enhancing factors in the high risk regions were associated with diet, such as protein and vitamin deficiences, hot beverages, hot and spicy foods, mouldy food, etc. ${ }^{9-11}$ The aetiology of oesophageal cancer in the moderate risk areas, including Japan, is our particular interest. In a previous paper we investigated the aetiology of oesophageal cancer in Saitama prefecture by a casecontrol method and described risk factors in terms of odds ratios. ${ }^{12}$ However we could not find any factors which were oustandingly likely to cause oesophageal cancer, attributable risks ranging from $20 \%$ to $50 \%$. It seems that the concept of multifactorial causation is required to understand the aetiology, and particularly that of competitive risk factors. ${ }^{13}$ In this paper we investigate the risk modification when two risk factors are combined, on the basis of joint distributions of cases and controls for two factors.

\section{Methods}

In an individually matched case-control study, 343 cases who died of cancer of the oesophagus between 
1973 and 1985 in the surveyed areas of Saitama prefecture were identified from the death certificates collected at local health centres. Our cases comprised about half of all the 635 deaths from oesophageal cancer. We omitted 106 subjects whose families had moved home and could not be contacted, and 186 subjects whose families could not remember the subjects' life style patterns clearly, or who refused to be interviewed for the survey. The population base for cases was about 15.3 million person-years. Controls were selected from Electoral Roll and were individually matched to cases with respect to sex, age (in two year age units), and neighbourhood. Three control candidates were selected for each case, who lived nearest, second nearest and third nearest to the case. About $60 \%$ of the first (nearest) candidates participated in this survey as controls. On refusal the subsequent candidates were considered for controls. The study comprised a total of 343 pairs, consisting of 257 male pairs and 86 female pairs. Mean age of cases at death was 68.3 years for males and 71.9 years for females. Mean age of male controls was 68.2 years and of female controls 71.5 years. Their residences were distributed over 44 administrative divisions (cities, towns and villages) out of a total of 92 divisions in Saitama. Controls were personally interviewed. Information about the cases was obtained from next of kin, $94 \%$ of whom had lived with the cases for longer than ten years (mode 30-39 years). All interviews were carried out by trained interviewers.

Time between death of cases and interview - The average elapsed time between death and interview of next of kin was 3.9 years, and $84 \%$ of interviews were within 6 years. Substitute respondents for cases were spouses (161/343), children (110), and other relations (72).

Questionnaire design - Our questionnaire has the following features:

(1) The frequency and amount of food intake were investigated for each of 12 nutritional food groups such as fruits, meat, fish, and green and yellow vegetables. Twelve other frequencies alone were determined for individual food items such as pickles, tea, coffee, smoked or baked meat/fish, and raw vegetables. Information about rice, a staple food, included the number of bowls consumed per day (one bowl contains about 110 grams of rice). We also enquired about the individual taste for salty foods and hot non-alcoholic beverages (including tea, coffee and miso-soup).

(2) Smoking and alcohol consumption were investigated in relation to change in use or consumption with time. We then calculated the total amounts of cigarettes and ethanol used over the subject's lifetime. There was a sex difference in smoking and alcohol consumption, only a few smokers or regular drinkers being female.
(3) "Dummy questions", which have no relation to oesophageal cancer, were included in order to examine the selection bias of controls: ie, TV viewing time and name of daily newspapers subscribed. We observed identical distributions between cases and controls on dummy questions, showing that there was little bias in control selection. ${ }^{12}$

Data collection on dead cases - There are three aspects of the problem of data collection on dead cases which merit consideration. (1) How reliable are the death certificates? (2) Is there a difference between mortality and incidence sufficient to influence the results? (3) How reliable are the case data?

We examined the accuracy of the diagnoses on the death certificate by comparing them with the pathological diagnoses for autopsy cases in Saitama. A total of 57 deaths in 1980 to 1982 were clinically diagnosed as oesophageal cancer and were followed by pathological diagnosis at autopsy. In four of these cases no oesophageal cancer was found at autopsy. In a further eight cases, autopsy showed oesophageal cancer which had not been diagnosed clinically. This low rate of erroneous diagnosis $(4 / 57,7 \%)$ supports the view that death certificates are reliable.

With respect to the difference between incidence and mortality data, we feel that this is small enough to be ignored since the 5 year survival rate of oesophageal cancer is very low at about $15 \%$.

As far as reliability of case data is concerned, we made the following efforts to achieve accuracy. Our questions on diet were simplified by grouping foods to enable substitute respondents to answer easily. Interviewed kin lived with the cases long enough to know their dietary habits, and the average time elapsed from the deaths to interviewing was about 4 years. In selection of cases, those subjects whose next of kin did not give reliable data were omitted. Additionally the interviewers were asked to categorise vague answers into "unknown", and in the analysis these "unknowns" were all omitted. Other studies focusing on this problem have shown that interview data on personal habits collected from substitute respondents are adequate for case-control analysis. ${ }^{14} 15$ The reliability of case data is still an important problem in this study, but this seems unavoidable as long as dead cases are used. However, we believe that our efforts have reduced the bias of case data sufficiently to avoid substantial distortion of our conclusions.

Our previous paper described risk enhancing and risk reducing factors in the occurrence of oesophageal cancer in terms of odds ratios, which were calculated from $2 \times 2$ tables for each of the factors and estimated as "single acting risks". These putative risk factors had odds ratios which were statistically significant for both sexes. ${ }^{12}$ In the present paper, we first obtained the joint distributions of cases and controls for every 
combination of two of the factors considered in this study. In the calculation, we only considered those paired data where both cases and matched controls fully answered the questions related to the two factors. Thus the total number of cases was equal to that of controls in each distribution, and we omitted the paired data in which either one of the pair failed to give enough answers for analysis. The age and geographical distributions of cases and controls concurred in every joint distribution of two factors. In the initial analysis of the results the joint distributions were obtained with a dichotomous exposure model with $2 \times 2$ tables for cases and controls. Odds ratios were then calculated for the joint distributions, together with $\chi^{2}$ values to test the null hyposthesis. ${ }^{16}$ Confidence limits were also calculated using the $\chi^{2}$ test. ${ }^{17}$

In our questionnaire, the intake of the various food groups was categorised into six ranks: $\leqslant$ once per week, 2-4 times, 5-7 times, 8-10 times, 11-13 times, $\geqslant 14$ times. Where, for example, "fruits F" or "meat F" is designated, this means that we only considered the frequency of intake, according to the above classification, and not the quantity of intake. The average amount of intake was determined by citing examples of the Japanese daily requirements, eg, the required amount of fruit was shown to respondents as one medium sized apple, or three small size mandarin oranges, or two bananas. The average amount consumed was then classified into three ranks: $>1.5$ times the daily requirement, about the daily requirement, and $<0.5$ times the daily requirement. We weighted the frequency responses by multiplying the median frequencies by 1.5 for first rank amounts, by 1.0 for second rank amounts, and by 0.5 for third rank amounts. The medians of the first and last ranks of frequency were replaced by 1 and 14 . This index of frequency weighted by amount is designated by, eg, "fruits FA" and "meat FA" in the results.

Interpretation and evaluation of epidemiological results often requires a description of the doseresponse relationship. This requirement can be applied to the joint effects of plural factors. It is then important to examine dose-response relations in the elevation and reduction of risk caused by combined factors. In the latter part of our analyses, odds ratios were calculated for males and females combined from the joint distributions of variously combined factors, using $3 \times 3$ tables for cases and controls and following a three exposure level model.

\section{Results}

JOINT EFFECTS OF TWO FACTORS ON ODDS RATIOS

We have classified combinations of two factors into three types: (1) two risk enhancing factors; (2) two risk reducing factors; (3) combination of risk enhancing and risk reducing factors. The results for the first, second and third types of factor combination are shown in tables 1,2 and 3, using a dichotomous exposure model. In the tables, a "single acting risk" means that the odds ratio was calculated from the distribution for a single factor. It is easily shown that the expected joint risk (odds ratio) of two factors is equal to the product of a single acting risk factor multiplied by that of another one, when no interactions exist between the factors. It can be seen in the tables that most of the observed joint risks were in the neighbourhood of the products of single risks.

The observed joint effects on risk modification in table 1 demonstrate the magnitude of risk amplication when two risk enhancing factors act together, and it is a warning for those concerned with cancer prevention how dramatically the risks increase when there is exposure to multiple risk enhancing factors. As we expected, combinations of potential risk enhancing factors gave higher joint risks. Since the highest risk was incurred by excessive intake of rice, combinations of rice and other risk enhancing factors showed high odds ratios of about 5 or more for males and 10 or more for females. A popular Japanese combination of rice and salty foods showed a particularly high odds ratio of 8.04 for males and 61.54 for females. In males a combination of alcohol abuse and salty foods showed the highest risk (odds ratios 10.91). In females combinations of salty foods and other risk enhancing factors also showed high odds ratios of around 7 or more. Females were more sensitive to dietary risk factors than males, but it is likely that most females were exempted from the dangers of cigarettes and alcohol use.

Table 2 demonstrates the remarkable joint effects in risk reduction when two risk reducing factors act together. Very low odds ratios of about 0.2 were observed with combinations of raw vegetables and other factors in males and of fruits and other factors in females. Adequate intakes of raw vegetables and fruits were found to be very protective, especially for males, though females seemed to require an additional intake of meat. A comparison of single acting risks of $F$ and FA in fruits and meat suggests that intake frequency was more essential for risk reduction than the amount.

Table 3 answers the important question of whether the elevated risk due to the exposure to a risk enhancing factor can be reduced or cancelled by a risk reducing factor. It can be seen from the table that each risk reducing factor reduced the risks of different combined factors in a multiplicative manner. This lack of selectivity of risk reducing effects is encouraging for cancer prevention. In males most risk enhancing factors could be cancelled by a single risk reducing 
Table 1 Joint odds ratios of two risk enhancing factors. 95\% confidence limits are shown in parentheses

(a) males

\begin{tabular}{|c|c|c|c|c|c|c|}
\hline & \multicolumn{6}{|c|}{ Risk enhancing factors } \\
\hline & Rice $^{a}$ & Alcohol $^{b}$ & Salty foods $c$ & Cigarettes $d$ & Spices $^{e}$ & Hot beverages $f$ \\
\hline Single acting risk & $\begin{array}{c}3 \cdot 320 \\
(2 \cdot 104 \\
5 \cdot 238)\end{array}$ & $\begin{array}{c}2.632 \\
(1.097- \\
6.315)\end{array}$ & $\begin{array}{c}2.392 \\
(1.659 \\
3.448)\end{array}$ & $\begin{array}{c}2.379 \\
(0.995 \\
5.690)\end{array}$ & $\begin{array}{c}2.050 \\
(1.397- \\
3.009)\end{array}$ & $\begin{array}{c}1.596 \\
(1.099 \\
2.317)\end{array}$ \\
\hline Alcohol & $\begin{array}{c}6.519 \\
(0.443- \\
96.027)\end{array}$ & & & & & \\
\hline Salty foods & $\begin{array}{c}8.038 \\
(4.170 \\
15.495)\end{array}$ & $\begin{array}{c}10.909 \\
(2.553- \\
46.614)\end{array}$ & & & & \\
\hline Cigarettes & nc & $\begin{array}{r}5.667 \\
(0.255- \\
125.936)\end{array}$ & $\begin{array}{l}3.029 \\
(0.898- \\
10 \cdot 217)\end{array}$ & & & \\
\hline Spices & $\begin{array}{c}4 \cdot 689 \\
(2 \cdot 350- \\
9 \cdot 357)\end{array}$ & $\begin{array}{c}3.911 \\
(1.023- \\
14.957)\end{array}$ & $\begin{array}{c}3.552 \\
(2 \cdot 182- \\
5.781)\end{array}$ & $\begin{array}{c}4.941 \\
(1.426 \\
17 \cdot 124)\end{array}$ & & \\
\hline Hot beverages & $\begin{array}{c}5.007 \\
(2.728- \\
9.190)\end{array}$ & $\begin{array}{c}3.706 \\
(0.965 \\
14.230)\end{array}$ & $\begin{array}{r}3.404 \\
(2.060- \\
5.625)\end{array}$ & $\begin{array}{c}3.091 \\
(0.967- \\
9.885)\end{array}$ & $\begin{array}{r}2.587 \\
(1.586 \\
4.219)\end{array}$ & \\
\hline
\end{tabular}

(b) females

\begin{tabular}{|c|c|c|c|c|c|c|}
\hline & \multicolumn{6}{|c|}{ Risk enhancing factors } \\
\hline & Rice & Salty foods & Spices & Cigarettes & Hot beverages & Alcohol \\
\hline Singe acting risk & $\begin{array}{c}8.126 \\
(3.525 \\
18.734)\end{array}$ & $\begin{array}{c}5.794 \\
(2.917- \\
11.508)\end{array}$ & $\begin{array}{c}3.150 \\
(1.252- \\
7.927)\end{array}$ & $\begin{array}{c}2.301 \\
(1.023- \\
5 \cdot 174)\end{array}$ & $\begin{array}{r}2 \cdot 167 \\
(1 \cdot 124 \\
4 \cdot 176)\end{array}$ & $1.055^{*}$ \\
\hline Salty foods & $\begin{array}{c}61.538 \\
(15.431- \\
245.417)\end{array}$ & & & & & \\
\hline Spices & nc & $\begin{array}{c}8 \cdot 500 \\
(2 \cdot 787 \\
25 \cdot 928)\end{array}$ & & & & \\
\hline Cigarettes & $\begin{array}{c}9 \cdot 714 \\
(2 \cdot 188- \\
43 \cdot 125)\end{array}$ & $\begin{array}{l}15 \cdot 340 \\
(3 \cdot 843 \\
61 \cdot 226)\end{array}$ & $\begin{array}{c}3.376 \\
(0.648 \\
17 \cdot 585)\end{array}$ & & & \\
\hline Hot beverages & $\begin{array}{c}13 \cdot 359 \\
(4 \cdot 209 \\
42 \cdot 399)\end{array}$ & $\begin{array}{c}8.400 \\
(3.376 \\
20.902)\end{array}$ & $\begin{array}{c}4.756 \\
(1.613 \\
14.027)\end{array}$ & $\begin{array}{r}4.000 \\
(1.349 \\
11.865)\end{array}$ & & \\
\hline Alcohol & $\begin{array}{c}6.111 \\
(1.544 \\
24.188)\end{array}$ & $\begin{array}{c}6 \cdot 514 \\
(2 \cdot 190 \\
19 \cdot 371)\end{array}$ & $\begin{array}{r}6.490 \\
(1.365 \\
30.848)\end{array}$ & $\begin{array}{c}2.016 \\
(0.512 \\
7.945)\end{array}$ & $\begin{array}{c}2.478 \\
(0.887 \\
6.919)\end{array}$ & \\
\hline
\end{tabular}

a Rice: more than or equal to 6 bowls per day/less for males, and more than $4 /$ less for females; ${ }^{b}$ alcohol: more than $800000 \mathrm{ml}$ of ethanol/less for males, and ever drank/never for females: ${ }^{c}$ salty foods: regular intake of very salty foods/moderately or lightly salted foods; ${ }^{\mathrm{d}}$ cigarettes: more than $400000 /$ less than for males, and ever-smoked/never for females; ${ }^{e}$ spices: high/moderate and low; ${ }^{t}$ hot beverages: high/moderate and low. $\chi^{2}$ value is almost zero. nc $=$ not computable due to no controls exposed to both the factors.

factor, though raw vegetables did not cancel the effects of cigarettes. However with some combinations the risk reduction was insufficient, for example in combinations of risk enhancing factors with weak risk reducing factors such as meat. Hence there was only a minor reduction in risk when such combinations as rice and meat, alcohol and meat, and salty foods and meat were eaten. In females the risk enhancing factors, rice and salty foods, were hardly cancelled by single risk reducing factors.

Risk enhancing factors are often associated with low exposure to risk reducing factors. For example, excessive intake of rice as a staple food is often accompanied in Japan by poor food variety and deficiency of other food items. In our study the proportions of subjects with excessive rice intakes who 
Table 2 Joint odds ratios of two risk reducing factors. $95 \%$ confidence limits are shown in parentheses.

(a) males

\begin{tabular}{|c|c|c|c|c|c|c|}
\hline & \multicolumn{6}{|c|}{ Risk reducing factors } \\
\hline & raw vegetables $a$ & Fruits $F^{b}$ & Fruits $F A^{c}$ & Seaweed $^{d}$ & Meat $F^{e}$ & Meat $F_{A} f$ \\
\hline Single acting risk & $\begin{array}{c}0.300 \\
(0.186- \\
0.496)\end{array}$ & $\begin{array}{c}0.311 \\
(0.216- \\
0.448)\end{array}$ & $\begin{array}{c}0.439 \\
(0.301- \\
0.641)\end{array}$ & $\begin{array}{c}0.417 \\
(0.288- \\
0.604)\end{array}$ & $\begin{array}{c}0.620 \\
(0.415- \\
0.926)\end{array}$ & $\begin{array}{c}0.742 \\
(0.508- \\
1.084)\end{array}$ \\
\hline Fruits F & $\begin{array}{c}0.151 \\
(0.086- \\
0.266)\end{array}$ & & & & & \\
\hline Fruits FA & $\begin{array}{c}0.179 \\
(0.101- \\
0.317)\end{array}$ & $\begin{array}{c}0.327 \\
(0.220- \\
0.487)\end{array}$ & & & & \\
\hline Seaweed & $\begin{array}{c}0.211 \\
(0.116- \\
0.385)\end{array}$ & $\begin{array}{c}0.174 \\
(0.106- \\
0.286)\end{array}$ & $\begin{array}{l}0.195 \\
(0.115- \\
0.331)\end{array}$ & & & \\
\hline Meat $\mathbf{F}$ & $\begin{array}{c}0.200 \\
(0.109 \\
0.368)\end{array}$ & $\begin{array}{c}0.248 \\
(0.149- \\
0.413)\end{array}$ & $\begin{array}{c}0.356 \\
(0.209 \\
0.606)\end{array}$ & $\begin{array}{c}0.287 \\
(0.169 \\
0.487)\end{array}$ & & \\
\hline Meat FA & $\begin{array}{c}0.242 \\
(0.132- \\
0.443)\end{array}$ & $\begin{array}{c}0.277 \\
(0.170- \\
0.452)\end{array}$ & $\begin{array}{c}0.386 \\
(0.234 \\
0.637)\end{array}$ & $\begin{array}{c}0.343 \\
(0.208 \\
0.565)\end{array}$ & $\begin{array}{c}0.625 \\
(0.406- \\
0.961)\end{array}$ & \\
\hline
\end{tabular}

(b) females

\begin{tabular}{|c|c|c|c|c|c|c|}
\hline & \multicolumn{6}{|c|}{ Risk reducing factors } \\
\hline & Fruits $F$ & Fruits $F A$ & Meat $F$ & Meat $F A$ & Raw vegetables & Seaweed \\
\hline Single acting risk & $\begin{array}{c}0.230 \\
(0.117- \\
0.453)\end{array}$ & $\begin{array}{c}0.345 \\
(0.162 \\
0.733)\end{array}$ & $\begin{array}{c}0.286 \\
(0.143- \\
0.571)\end{array}$ & $\begin{array}{c}0.750 \\
(0.361- \\
1.559)\end{array}$ & $\begin{array}{c}0.418 \\
(0.182 \\
0.959)\end{array}$ & $\begin{array}{c}0.440 \\
(0.218- \\
0.889)\end{array}$ \\
\hline Fruits FA & $\begin{array}{c}0.257 \\
(0.119 \\
0.554)\end{array}$ & & & & & \\
\hline Meat $\mathbf{F}$ & $\begin{array}{c}0.089 \\
(0.033- \\
0.238)\end{array}$ & $\begin{array}{c}0.118 \\
(0.039 \\
0.357)\end{array}$ & & & & \\
\hline Meat FA & $\begin{array}{c}0.189 \\
(0.074 \\
0.482)\end{array}$ & $\begin{array}{c}0.290 \\
(0.105- \\
0.800)\end{array}$ & $\begin{array}{c}0.337 \\
(0.153- \\
0.743)\end{array}$ & & & \\
\hline Raw vegetables & $\begin{array}{c}0.164 \\
(0.061- \\
0.444)\end{array}$ & $\begin{array}{c}0.188 \\
(0.065- \\
0.541)\end{array}$ & $\begin{array}{c}0.144 \\
(0.049 \\
0.427)\end{array}$ & $\begin{array}{c}0.273 \\
(0.070 \\
1.065)\end{array}$ & & \\
\hline Seaweed & $\begin{array}{c}0.124 \\
(0.046- \\
0.332)\end{array}$ & $\begin{array}{c}0.147 \\
(0.049 \\
0.437)\end{array}$ & $\begin{array}{c}0.149 \\
(0.054 \\
0.410)\end{array}$ & $\begin{array}{c}0.303 \\
(0.108- \\
0.849)\end{array}$ & $\begin{array}{c}0.249 \\
(0.076 \\
0.819)\end{array}$ & \\
\hline
\end{tabular}

$\mathrm{F}=$ frequency only. FA $=$ frequency weighted for quantity (see Methods)

a Raw vegetables: more than or equal to 6 times per week/less; ${ }^{b}$ fruits F: more than 5 times per week/less; ${ }^{c}$ fruits FA: more than $5 \cdot 0$ of weighted frequency/less:

d seaweed: more than 5 per week/less; ${ }^{\mathrm{e}}$ meat $\mathrm{F}$ : more than 2 per week/less; ${ }^{f}$ meat FA: more than $2 \cdot 0$ of weighted frequency/less.

also ate more than the target level of meat, raw vegetables and fruits were 81,21 and $65 \%$ respectively in controls and 55, 10 and $33 \%$ in cases (males and females combined). Excessive intake of rice without supplements of other foods of good nutrient value was observed more often in cases, and thus worked to increase the risk. Similarly, the proportions of subjects with high intake of salty foods who also ate more than the target level of meat, raw vegetables and fruits were 72,22 and $61 \%$ respectively in controls and 58,11 and $37 \%$ in cases. The risk enhanced by rice or salty foods can be partly ascribed to insufficient intake of foods containing risk reducing factors.
DOSE-RESPONSE RELATIONS IN JOINT EFFECTS Figures 1,2 and 3 show the typical dose-response relations observed in the joint effects of two risk enhancing factors, two risk reducing factors, and combinations of a risk enhancing and a risk reducing factor, taking as respective examples rice and salty foods, raw vegetables and fruits, and rice and fruits. In fig 1 a positive dose-response relation was observed for intake of rice (salty foods) in each category of salty foods (rice). The highest risk of $16 \cdot 15$ was then found at category $3 \times 3$. This multiplicative elevation of risk was commonly observed for other combinations of two risk enhancing factors (another example being 
Table 3 Joint odds ratios of risk enhancing and reducing factors. 95\% confidence limits are shown in parentheses (a) males

\begin{tabular}{|c|c|c|c|c|c|c|c|}
\hline & & \multicolumn{6}{|c|}{ Risk enhancing factors } \\
\hline & & Rice & Alcohol & Salty Foods & Cigarettes & Spices & Hot beverages \\
\hline \multicolumn{8}{|c|}{ Risk reducing factors: } \\
\hline & $\begin{array}{l}\text { Single } \\
\text { risk }\end{array}$ & $\begin{array}{l}3 \cdot 320 \\
(2 \cdot 104 \\
5 \cdot 238)\end{array}$ & $\begin{array}{c}2.632 \\
(1.097 \\
6.315)\end{array}$ & $\begin{array}{r}2.392 \\
(1.659 \\
3.448)\end{array}$ & $\begin{array}{r}2.379 \\
(0.995 \\
5.690)\end{array}$ & $\begin{array}{c}2.050 \\
(1.397- \\
3.009)\end{array}$ & $\begin{array}{r}1.596 \\
(1.099 \\
2.317)\end{array}$ \\
\hline Raw vegetables & $\begin{array}{c}0.300 \\
(0.189 \\
0.476)\end{array}$ & $\begin{array}{r}0.869 \\
(0.000 \\
5.231)\end{array}$ & $0.000 t$ & $\begin{array}{c}0.772 \\
(0.268 \\
2.223)\end{array}$ & $2 \cdot 520^{*}$ & $\begin{array}{c}0.520 \\
(0.239 \\
1.132)\end{array}$ & $\begin{array}{c}0.465 \\
(0.240- \\
0.900)\end{array}$ \\
\hline Fruits F & $\begin{array}{c}0.311 \\
(0.216 \\
0.448)\end{array}$ & $\begin{array}{c}0.953 \\
(0.048- \\
18.833)\end{array}$ & $\begin{array}{c}0.800 \\
(0.010 \\
63.464)\end{array}$ & $\begin{array}{c}0.734 \\
(0.399 \\
1.351)\end{array}$ & $\begin{array}{c}0.692 \\
(0.108- \\
4.432)\end{array}$ & $\begin{array}{c}0.613 \\
(0.335 \\
1 \cdot 121)\end{array}$ & $\begin{array}{c}0.529 \\
(0.311- \\
0.900)\end{array}$ \\
\hline Fruits FA & $\begin{array}{c}0.439 \\
(0.301- \\
0.641)\end{array}$ & $\begin{array}{c}1.416 \\
(0.709 \\
2.826)\end{array}$ & $\begin{array}{c}1.368 \\
(0.147- \\
12.694)\end{array}$ & $\begin{array}{c}1.013 \\
(0.763- \\
1.344)\end{array}$ & $\begin{array}{c}0.929 \\
(0.249 \\
3.470)\end{array}$ & $\begin{array}{c}0.848 \\
(0.414 \\
1.737)\end{array}$ & $\begin{array}{c}0.745 \\
(0.402- \\
1.379)\end{array}$ \\
\hline Seaweed & $\begin{array}{c}0.417 \\
(0.288- \\
0.604)\end{array}$ & $\begin{array}{c}1.283 \\
(0.462- \\
3.560)\end{array}$ & $\begin{array}{c}1.500 \\
(0.320- \\
7.023)\end{array}$ & $\begin{array}{c}0.990 \\
(0.813 \\
1.206)\end{array}$ & $\begin{array}{c}1.463 \\
(0.245- \\
8.743)\end{array}$ & $\begin{array}{c}0.915 \\
(0.311- \\
2.694)\end{array}$ & $\begin{array}{c}0.675 \\
(0.379 \\
1.201)\end{array}$ \\
\hline Meat F & $\begin{array}{c}0.620 \\
(0.415- \\
0.926)\end{array}$ & $\begin{array}{c}1.991 \\
(1.023- \\
3.875)\end{array}$ & $\begin{array}{c}1.700 \\
(0.359 \\
8.054)\end{array}$ & $\begin{array}{c}1.676 \\
(0.908- \\
3.093)\end{array}$ & $\begin{array}{c}2.031 \\
(0.435- \\
9.493)\end{array}$ & $\begin{array}{c}1.275 \\
(0.668- \\
2.433)\end{array}$ & $\begin{array}{c}0.986 \\
(0.737- \\
1.319)\end{array}$ \\
\hline Meat FA & $\begin{array}{c}0.742 \\
(0.508 \\
1.084)\end{array}$ & $\begin{array}{c}2 \cdot 126 \\
(1 \cdot 133- \\
3 \cdot 991)\end{array}$ & $\begin{array}{c}2.615 \\
(0.583- \\
11.734)\end{array}$ & $\begin{array}{c}1.805 \\
(1.031- \\
3.160)\end{array}$ & $\begin{array}{c}1.754 \\
(0.353- \\
8.714)\end{array}$ & $\begin{array}{c}1.434 \\
(0.808- \\
2.546)\end{array}$ & $\begin{array}{c}1 \cdot 186 \\
(0.625 \\
2.252)\end{array}$ \\
\hline
\end{tabular}

(b) females

Risk enhancing factors

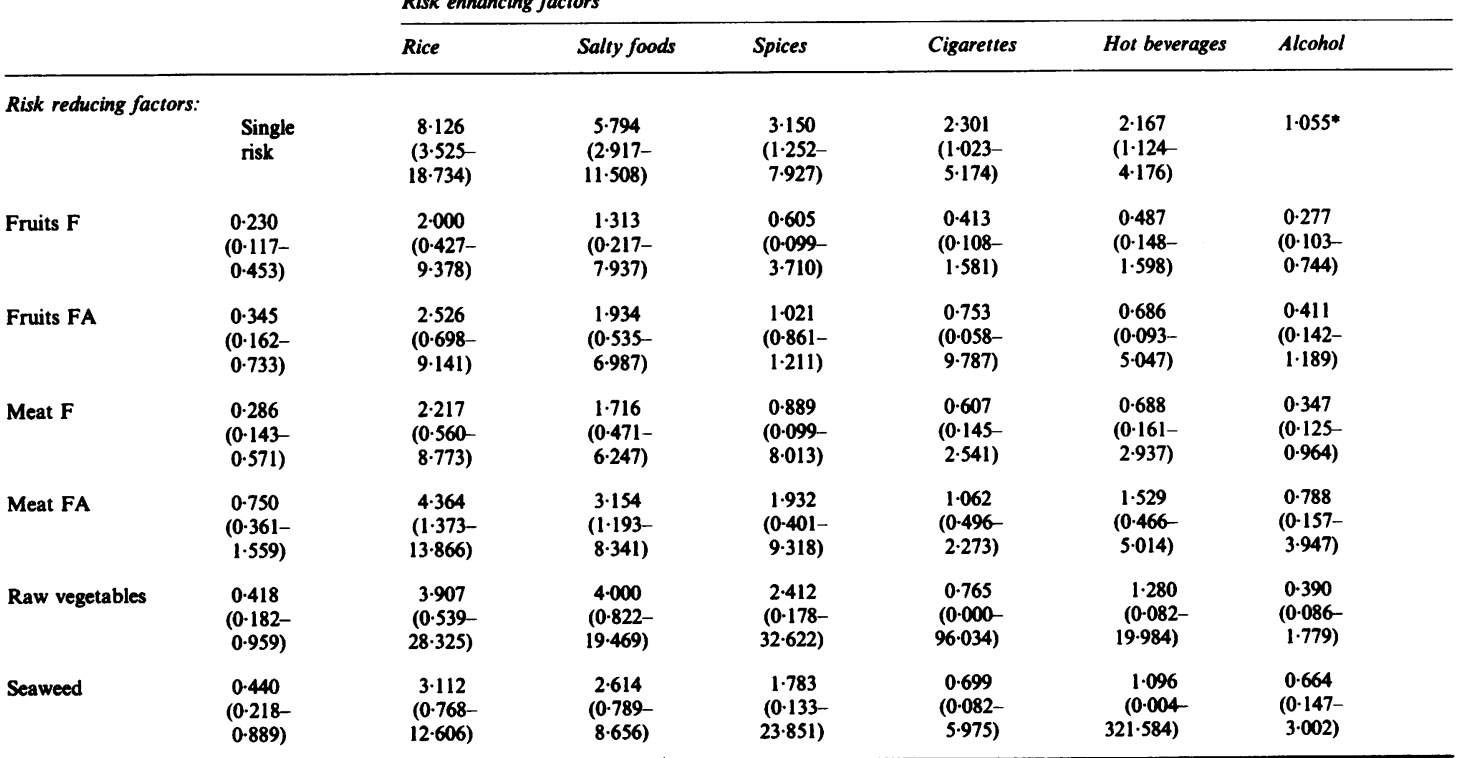

t Cases exposed to both factors are null

- $\chi^{2}$ value is almost zero

shown in table 4). Excessive intake of rice among heavy smokers and drinkers was shown to be a very high risk factor (see the risk of 19.25 in category $3 \times 3$ of rice and cigarettes in table 4 , and the odds ratio in category $3 \times 3$ of rice and alcohol was $13.82, p<0.01$ ).
This drastic risk elevation was not seen in other combinations of risk enhancing factors.

The dose-response relation of two risk reducing factors in fig 2 shows the multiplicative reduction in risk, although the risk of 0.05 in category $3 \times 3$ of raw 


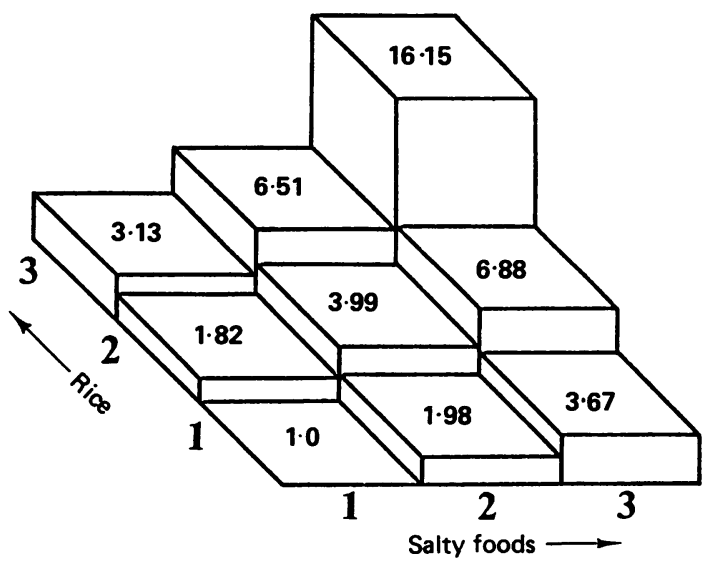

Fig 1 A typical pattern of dose-response relations of two risk enhancing factors. Joint risk of rice and salty foods with three exposure levels (rice: category 1 for $<4$ bowls per day taking single risk to be $1 \cdot 0$, category 2 for 4-7 bowls with single risk of 1.941 , category $3 \geqslant 8$ with risk of 4.306; salty foods: category 1 for less salty foods taking risk of $1 \cdot 0$, category 2 for moderate saltiness with risk of $2 \cdot 203$, category 3 for very salty foods, with risk of 4.430).

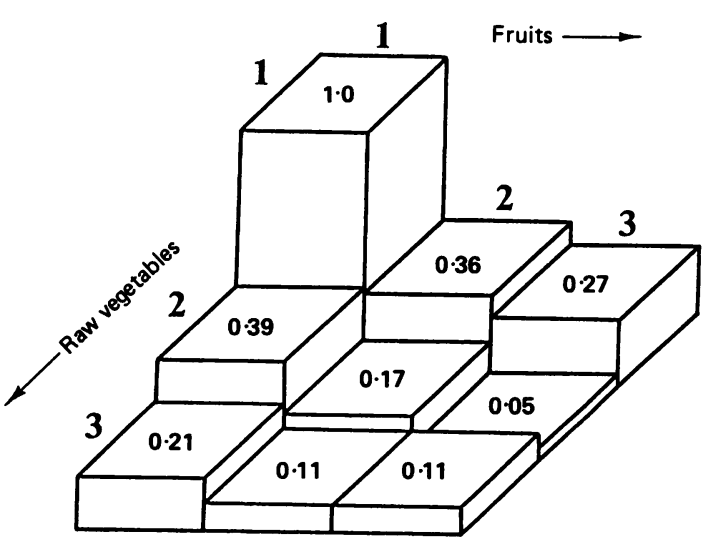

Fig 2 A typical dose-response relation of two risk reducing factors. Joint risk of fruits and raw vegetables (fruit $F$ : category 1 for $<5$ times per week taking risk to be $1 \cdot 0$, category 2 for 5-7 times with risk of $0 \cdot 331$, category 3 for $\geqslant 8$ times with risk of 0.176; raw vegetables: category 1 for $<2$ times per week taking risk to be $1 \cdot 0$, category 2 for 2-5 times with risk of $0 \cdot 343$, category 3 for $\geqslant 6$ times with risk of $0 \cdot 198)$.

Table 4 Joint risk of rice and cigarettes with three exposure levels. 95\% confidence limits are shown in parentheses

\begin{tabular}{|c|c|c|c|c|}
\hline & & Cigarettes* I & Cigarettes 2 & Cigarettes 3 \\
\hline Ricet 3 & $\begin{array}{l}4 \cdot 306 \\
(2 \cdot 807-6 \cdot 605)\end{array}$ & $\begin{array}{l}5.133 \\
(2 \cdot 179-12.092)\end{array}$ & $\begin{array}{l}3.025 \\
(1.344 \quad 6.808)\end{array}$ & $\begin{array}{l}19 \cdot 250 \\
(3 \cdot 412-108.618)\end{array}$ \\
\hline Rice 2 & $\begin{array}{l}1.941 \\
(1.308-2.879)\end{array}$ & $\begin{array}{l}5.005 \\
(1.625-15.411)\end{array}$ & $\begin{array}{l}2.005 \\
(0.958 \quad 4.195)\end{array}$ & $\begin{array}{l}4.813 \\
(1.341-17 \cdot 271)\end{array}$ \\
\hline \multirow[t]{2}{*}{ Rice 1} & 1.0 & 1.0 & $\begin{array}{l}1.481 \\
(0.790-2.775)\end{array}$ & $\begin{array}{l}2.310 \\
(0.809-6.593)\end{array}$ \\
\hline & Single risk & 1.0 & $\begin{array}{l}1 \cdot 142 \\
(0.685-1 \cdot 904)\end{array}$ & $\begin{array}{l}2.521 \\
(1 \cdot 230-5 \cdot 166)\end{array}$ \\
\hline
\end{tabular}

- Cigarettes: category 1 for never-smokers, category 2 for $<400000$ cigarettes, category 3 for $\geqslant 400000$

† Rice: category $1<4$ bowls per day, category $24-7$ bowls, category $3 \geqslant 8$ bowls

Table 5 Joint risk of fruits and seaweed. 95\% confidence intervals in parentheses

\begin{tabular}{|c|c|c|c|c|}
\hline & & Seaweed* 1 & Seaweed 2 & Seaweed 3 \\
\hline Fruitt F 3 & $\begin{array}{l}0.176 \\
(0.102-0.304)\end{array}$ & $\begin{array}{l}0 \cdot 126 \\
(0.013-1 \cdot 186)\end{array}$ & $\begin{array}{l}0.059 \\
(0.019-0.184)\end{array}$ & $\begin{array}{l}0.061 \\
(0.0240 .152)\end{array}$ \\
\hline Fruit F 2 & $\begin{array}{l}0.33 \dot{1} \\
(0.237-0.463)\end{array}$ & $\begin{array}{l}0.208 \\
(0.065-0.665)\end{array}$ & $\begin{array}{l}0.133 \\
(0.0640 .276)\end{array}$ & $\begin{array}{l}0.097 \\
(0.0470 .199)\end{array}$ \\
\hline Fruit F 1 & $\begin{array}{l}1.0 \\
\text { Single risk }\end{array}$ & 1.0 & $\begin{array}{l}0.429 \\
(0.190-0.967) \\
0.410 \\
(0.239-0.702)\end{array}$ & $\begin{array}{l}0.181 \\
(0.083-0.393) \\
0.210 \\
(0.1250 .354)\end{array}$ \\
\hline
\end{tabular}

* Category $1:<2$ times per week; category 2: 2-4 times; category 3: $\geqslant 5$ times

† Fruit F: category $1<5$ times per week, category $25-7$ times per week, category $3 \geqslant 8$ times per week 
vegetables and fruits was much lower than the expected value. The observed odds ratio of 0.11 in category $3 \times 3$ was much higher than the expected value of $0.035(=0.176 \times 0.198)$. This saturation of risk reduction in category $3 \times 3$ was commonly observed in other combinations. Table 5 shows the combination of fruits and seaweed.

Combinations of risk enhancing and risk reducing factors are of much interest to us. The dose-response relation was observed in fig 3 and table 6 . In fig 3, a positive (negative) dose-response relation was observed for intake of rice (fruit) in each category of fruit (rice) intake. In other words the increased risk due to a risk enhancing factor is reduced by stages which correspond to the dose levels of a combined risk reducing factor. Remarkable risk elevations due to excessive intake of rice were commonly observed, specifically to category $1 \times 3$, which means a serious lack of risk reducing factors.

Finally it is emphasised that the dose-response relations were observed in all the combinations of factors, although we only show typical examples in this paper.

\section{Discussion}

Multifactorial approaches to cancer aetiology are indispensable for estimating the risks to individuals as a whole, and for revealing interrelated causes. To pursue these aims, the joint effects of at least two combined factors must first be revealed. Our results in this paper meet this requirement, and show (1) that the observed joint risk of two factors was approximated by the multiplicative product of single acting risks for individual factors; (2) that risk reduction by a particular factor was non-selective and capable of opposing a number of risk enhancing factors; and (3) that typical patterns of dose-response relations were clearly observed in combinations of two risk enhancing factors, two risk reducing factors, and simultaneous consumption of enhancing and reducing factors. The first and second of these observations also imply that we found no such dependent relations among factors in this study in which one factor required another one(s) to reveal its effects. This may indicate that the epidemiological factors we obtained have multiple risk enhancing or reducing effects, acting at various stages of carcinogenesis (including the exposure of cells to carcinogens and the growth of malignant cells). The multiplicative risk elevation with two enhancing factors allows us to guess the risk resulting from the simultaneous action of three or more factors, eg, the joint risk of three risk enhancing factors (or deficiencies of reducing factors) will be extremely high, of the order 10 - to 100 -fold. It is thus important in the primary prevention of cancer to avoid exposure to multiple risk enhancing factors. This

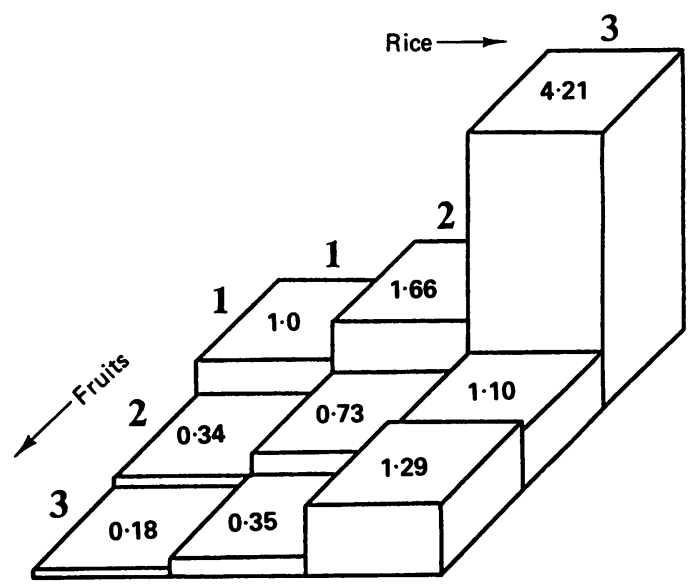

Fig 3 A typical dose-response relation of risk enhancing and reducing factors. Joint risk of rice and fruits.

concept of multiple factors is also important for screening high risk groups. ${ }^{1318} 19$ The second observation means that risk reducing factors show protective effects, whatever risk enhancing factors one may be exposed to. The third observation not only confirms the validity of our first observation but proposes three typical patterns of the dose-response relations involving two factors. These patterns can be well explained by the dose-response relations of single acting risks and by the multiplicative modification in joint risks, although some combinations or elements were found to be much more than the expected values in a multiplicative model. The above mentioned independence of factors may be related to the fact that most of the risk enhancing factors we obtained are not carcinogenic but seem to cause disruptive damage to the mucosal lining of the oesophagus and thus to cause the cells to be exposed to various ingested carcinogens. ${ }^{20}$ The effects of thermal injury by hot beverages, a taste for salty foods, an excessive intake of spicy foods and alcohol abuse could all operate by this mechanism, and other published evidence is consistent

with this. ${ }^{21-24}$ Recent animal experiments suggested that salt and alcohol act as co-carcinogens for oesophageal cancer. ${ }^{25}$ Excessive intake of rice, however, may operate by causing a deficiency of protective micronutrients. It has been shown that a diet of rice as the staple food caused a deficiency of protective micronutrients, including riboflavin, nicotinic acid and zinc (in which rice is deficient), unless these were provided from other sources. ${ }^{26}$ The risk reducing factors in this study were also consistent with those found in other epidemiological studies. ${ }^{242728}$ The importance of vitamin $\mathrm{C}$ was emphasised by the 
Table 6 Joint risk of cigarettes and fruits. 95\% confidence limits in parentheses. For Cigarette categories see table 4. For Fruits F categories see table 5

\begin{tabular}{llll}
\hline & Fruits F 1 & Fruits $F 2$ & Fruits F 3 \\
\hline Cigarettes 3 & 1.699 & 0.805 & 0.537 \\
& $(0.413-6.994)$ & $(0.002-328.852)$ & $(0.008-36.900)$ \\
Cigarettes 2 & 1.073 & 0.248 & 0.134 \\
& $(0.014-84.565)$ & $(0.120-0.513)$ & $(0.025-0.727)$ \\
Cigarettes 1 & 1.0 & 0.335 & 0.149 \\
& & $(0.163-0.691)$ & $(0.048-0.461)$ \\
\hline
\end{tabular}

observed protective effects of fruits and raw vegetables. It is likely that vitamin $\mathrm{C}$, by blocking the formation of nitrosocompounds, plays a more important role than vitamin $\mathbf{A}$ in protecting against oesophageal cancer. ${ }^{24} 29$ The origin of the protective effects of meat may be complex: for example as a source of protein in relation to immune function, and as a source of riboflavin, nicotinic acid and zinc. Seaweed also contains considerable amounts of riboflavin and zinc.

Risk enhancing factors for cancer can be roughly classified into two types: genotoxic and epigenetic. ${ }^{24}$ Using this classification, most of the risk enhancing factors we found were of the epigenetic type, which promote carcinogenesis through mucosal damage or which act as co-carcinogens. They require other genotoxic or/and enhancing factors. The remarkable increase in risk observed with combinations of factors indicates that the incidence of oesophageal cancer in our prefecture is caused by the joint effects of multiple risk enhancing factors, or by risk enhancing factors combined with the insufficient exposure to risk reducing factors. Among the various risk enhancing factors found in our study excessive intake of rice and deficient intake of meat may not be generally applicable to most other populations except for some of the other Asian countries. The predominant factors may differ in different populations, although the increased risk caused by combinations of risk enhancing factors (in the absence of risk reducing factors) seems to be important in the aetiology, whatever the nature of the predominant enhancing factors. The conclusions of this paper on the joint effect of risk associating factors can be applied as a model for other studies in this area.

Finally we must mention again the potential problem of the reliability of case data collected from the next of kin. In this study we examined the adequacy of substitute respondents in terms of the time of living together or the time elapsed from the death of cases, but the bias of the data was not exactly assessed. We still think that our results can be accepted, for the two main reasons: (1) The dietary items of the questionnaire were restricted to the main food groups and other conspicuous items, avoiding details of the diet; and (2) All the significant factors in this study showed a dose-response relationship. The reliability of data partly depends on the itemisation or categorisation of foods in the questionnaire, ie, detailed questions often lower the reliability of answers, and thus are not adequate for studies of this kind. Dose-response relationships carry considerable weight, especially in this study, because such relationships are difficult to demonstrate when unreliable data are used. However a correct assessment of the bias in data of dead cases is important, and this still remains in question.

Authors are grateful to Dr Y Tagashira, President of the Saitama Cancer Center Research Institute, for his great help in managing this research project.

Address for correspondence and reprints: $\mathrm{Dr} \mathrm{K}$ Nakachi, Department of Epidemiology, Saitama Cancer Center Research Institute, 818 Komuro, Inamachi, Kitaadachi-Gun, Saitama-ken 362, Japan.

\section{References}

${ }^{1}$ Kurihara M, Aoki K, Tominaga S, eds. Cancer mortality statistics in the world. Nagoya, Japan: The University of Nagoya Press, 1984.

2 Waterhouse J, Muir CS, Correa P, Powell J, eds. Cancer incidence in five continents. Lyon: IARC Sci Publ No. 15, 1976.

${ }^{3}$ Mahboubi EO, Kmet J, Cook PJ, Day NE, Ghadirian P, Salmasrjadeh $S$. Oesophageal cancer studies in the Caspian littoral of Iran: the Caspian cancer registry. $\mathrm{Br} J$ Cancer 1973; 28: 197-214.

${ }^{4}$ Rose EF, McClashan ND. The spatial distribution of oesophageal carcinoma in the Transkei, South Africa. $\mathrm{Br}$ $J$ Cancer 1975; 31: 197-206.

${ }^{5}$ Bashirov MS, Nugmanov SN, Kolychva NI. Epidemiology of esophageal cancer in the Aktrubinsk of Kazakh SSR. Vopr Onkol 1968; 14: 3-6.

${ }^{6} \mathrm{Li} \mathrm{KH}, \mathrm{KaO}$ JC, Wu YK. A survey of the prevalence of cancer of the esophagus in north China. Chinese Med J 1962; 81: 489-94. 
${ }^{7}$ Tuyns AJ, Pequignot G, Jensen OM. Oesophageal cancer in Illet-et-Vilain in relation to alcohol and tobacco consumption: multiplicative risks. Bull Cancer 1977; 64(1): 45-60 (in French).

${ }^{8}$ Wynder EL, Bross IJ. A study of etiological factors in cancer of the esophagus. Cancer 1961; 14: 389-413.

${ }^{9}$ Martinez I. Factors associated with cancer of the esophagus, mouth, and pharynx in Puerto Rico. $J$ Natl Cancer Inst 1969; 42: 1069-94.

${ }^{10}$ Mahboubi EO, Aramesh B. Epidemiology of esophageal cancer in Iran, with special reference to nutritional and cultural aspects. Prev Med 1980; 9: 613-21.

11 Yang CS. Research on esophageal cancer in China: a review. Cancer Res 1980; 40: 2633-44.

12 Tagashira Y, Sasaba T, Nakachi K, Imai K, Hoshiyama Y. Epidemiology of esophageal cancer in Saitama, Japan: a case-control study. Jpn J Public Health 1987; 34: 589-97 (in Japanese, with English summary).

${ }^{13}$ Epstein FH. Epidemiological research strategies for multiple factor studies. Activitas Nervosa Superior (Praha) 1982; Suppl 3: 30-8.

${ }^{14}$ Kolonel LN, Hirohata T, Nomura AMY. Adequacy of survey data collected from substitute respondents. Am J Epidemiol 1977; 106: 476-84.

${ }^{15}$ Marshall J, Priore R, Haughey B, Rzepka T, Graham S. Spouse-subject interviews and the reliability of diet studies. Am J Epidemiol 1980; 112: 675-83.

16 Mantel N. Chi-square tests with one degree of freedom: extensions of the Mantel-Haenszel procedure. $\mathrm{J} \mathrm{Am}$ Statist Assoc 1963; 58: 690-700.

${ }^{17}$ Miettinen OS. Estimability and estimation in casereferrent studies. Am J Epidemiol 1976; 103: 226-35.

18 Weiss NS, Liff JM. Accounting for the multicausal nature of disease in the design and analysis of epidemiologic studies. Am J Epidemiol 1983; 117: 14-18.

${ }^{19}$ Walter SD. Prevention for multifactorial diseases. Am J Epidemiol 1980; 112: 409-16.
${ }^{20}$ Neuberger JS. Cancer of the esophagus: a model of causation. Med Hypotheses 1982; 9: 337-42.

${ }^{21}$ Yioris N, Ivankovic S, Lehnert T. Effect of thermal injury and oral administration of N-methyl-N'-nitro-Nnitrosoguanidine on the development of esophageal tumours in wistar rats. Oncology 1984; 41: 36-8.

22 Hopkins RA, Postlethwait RW. Causatic burns and carcinoma of the esophagus. Ann Surg 1981; 194: 146-8.

${ }^{23} \mathrm{Lu} \mathrm{JB}$, Qin YM. Correlation between high salt intake and mortality rates for oesophageal and gastric cancers in Henan province, China. Int J Epidemiol 1987; 16: 171-6.

24 Weisburger JH, Wynder EL, Horn CL. Nutritional factors and etiologic mechanisms in the causation of gastrointestinal cancers. Cancer 1982; 50: 2541-9.

25 Konishi N, Kitahori Y, Shimoyama T, Takahashi M, Hiasa $Y$. Effects of sodium chloride and alcohol on experimental esophageal carcinogenesis induced by $\mathrm{N}$ nitrosopiperidine in rats. Jpn J Cancer Res (Gann) 1986; 77: 446-51.

${ }^{26}$ van Rensburg SJ. Epidemiologic and dietary evidence for a specific nutritional preposition to esophageal cancer. $J$ Natl Cancer Inst 1981; 67: 243-51.

${ }^{27}$ Doll R, Peto R. The causes of cancer. New York: Oxford University Press, 1981.

${ }^{28}$ Mettlin C, Graham S, Priore R, Marshall J, Swanson M. Diet and cancer of the esophagus. Nutr Cancer 1981; 2: 143-7.

${ }^{29}$ Lu SH, Ohshima H, Fu HM, Tian Y, Li FM, Blettner M, Wahrendorf $J$, Bartsch $H$. Urinary excretion of $\mathrm{N}$-nitrosamino acids and nitrate by inhabitants of highand low-risk areas for esophageal cancer in northern China: endogenous formation of nitrosoproline and its inhibition by vitamin C. Cancer Res 1986; 46: 1485-91.

Accepted for publication July 1988 